\title{
A Rare Cause of Shoulder Pain: Monostotic Fibrous Dysplasia
}

\author{
Bayram KELLE, ${ }^{1}$ Aygül POLAT KELLE, ${ }^{2}$ Kıvılcım EREN ERDOĞAN, ${ }^{3}$ Erkan KOZANOĞLU ${ }^{1}$ \\ ${ }^{1}$ Department of Physical Medicine and Rehabilitation, Medical Faculty of Çukurova University, Adana, Turkey \\ ${ }^{2}$ Department of Nuclear Medicine, Adana Numune Training and Research Hospital, Adana, Turkey \\ ${ }^{3}$ Department of Pathology, Medical Faculty of Çukurova University, Adana, Turkey
}

\begin{abstract}
Fibrous dysplasia is a rare bone disease which has a wide spectrum of symptoms depending on the involvement area such as pain, deformity, fracture, dyspnea or visual loss. One of the rare involvement areas is the bones around the shoulder. Fibrous dysplasia presents in two forms named monostotic or polyostotic. In this article, we present a case with monostotic fibrous dysplasia of the humeral head who admitted to our clinic with shoulder pain.

Keywords: Fibrous dysplasia; humerus; shoulder; shoulder pain
\end{abstract}

Shoulder pain is one of the most common musculoskeletal problems in the community, ${ }^{1}$ constituting $16 \%$ of all musculoskeletal system complaints. ${ }^{2}$ Various causes of shoulder pain have been described arising from extra and intraarticular structures. Although the most common causes of shoulder pain including local musculoskeletal problems are benign, serious inflammatory, malign and other systemic problems must be considered in a patient presenting with shoulder pain.

Fibrous dysplasia (FD) of bone is a rare disease often associated with severe clinical outcome, including bone pain, deformities, and fractures. ${ }^{3}$ FD presents in monostotic form which affects one bone or in polyostotic form which affects several bones. ${ }^{4}$ In this article, we present a case of monostotic FD in humeral head which is a rare cause of shoulder pain and review the current literature.

\section{CASE REPORT}

A 37-year-old male patient admitted to Physical Medicine and Rehabilitation outpatient clinic due to increased pain at right shoulder for about six months. Patient did not report any trauma to the shoulder area. Although his pain increased with motion, shoulder pain persisted even at rest. Patient had benefited from analgesic medication initially but he stated that his pain increased over time. A written informed consent was obtained from the patient.

On physical examination, his general status was well. Range of motion of the right shoulder joint was minimally limited (flexion and extension in sagittal plane $160^{\circ}$ and $40^{\circ}$; abduction and adduction in frontal plane $165^{\circ}$ and $50^{\circ}$, respectively). The provocative tests were negative excluding minimally painful shoulder range of motion. 
Laboratory analysis did not reveal any abnormality. Results of the analysis were as follows; hemoglobin: $15.2 \mathrm{~g} / \mathrm{dL}$ (normal: 13.6-17.21), hematocrit: $45.4 \%$ (normal: 39.5-50.3), erythrocyte sedimentation rate: $4 \mathrm{~mm} /$ hour (normal: 0-15), C-reactive protein: $0.327 \mathrm{ng} / \mathrm{L}$ (normal: 0-0.8), alkaline phosphatase: $54 \mathrm{u} / \mathrm{L}$ (normal: 38-126), plasma creatinin: $0.77 \mathrm{mg} / \mathrm{dL}$ (normal: 0.7-1.2), white blood cell count: $7.27 \times 10^{3} / \mu \mathrm{L}$ (normal: $4.5-10.3$ ), aspartate aminotransferase: $20 \mathrm{U} / \mathrm{L}$ (normal: 15-41), alanine aminotransferase: $18 \mathrm{U} / \mathrm{L}$ (normal: 17-63), calcium: $8.9 \mathrm{mg} / \mathrm{dL}$ (normal: 8.9-10.3), phosphorus: $3.3 \mathrm{mg} / \mathrm{dL}$ (normal: 2.7-4.5), and thyroid stimulating hormone: $0.48 \mathrm{mIU} / \mathrm{L}$ (normal: 0.34-5.60). Bone turnover markers including osteocalcin and C-terminale telopeptide were in normal range [osteocalcin: $58.29 \mathrm{ng} / \mathrm{mL}$ (normal: 0-1000), C-terminale telopeptide: $0.176 \mathrm{ng} / \mathrm{mL}$ (normal: 0.01-0.584)].

Plain X-ray of the right shoulder revealed a lytic area at humeral head (Figure 1a). Right humeral magnetic resonance imaging revealed a hyperintense area with a dimension of $3.7 \times 2.3 \mathrm{~cm}$ at fat-saturated $\mathrm{T}_{2}$ sequence (Figure $1 \mathrm{~b}$ ). Whole body bone scintigraphy demonstrated increased uptake at proximal part of right humerus (Figure 1c). Low power photomicrograph of biopsy specimen showed delicate trabeculae of woven bone in moderately cellular fibrous matrix with focal areas of degenerative bone fragments (Figure 1d-e). On higher magnification, nonlamellar bone and bland spindle-cell fibrous stroma were also seen (Figure 1f). As a result, a diagnosis of monostotic FD of humerus was established. Oral alendronate $35 \mathrm{mg} /$ week was prescribed. Patient reported a significant decrease of pain after three months.

\section{DISCUSSION}

Fibrous dysplasia is an abnormal growth pattern characterized by fibro-osseous replacement of mature marrow with immature abnormal matrix. The abnormal production of fibroconnective tissue is due to a mutation in the GNAS1 gene. ${ }^{4}$

Fibrous dysplasia constitutes $2.5 \%$ to $7 \%$ of benign bone tumors. ${ }^{5}$ FD has two subtypes which are polyostotic or monostotic. Polyostotic form has a serious prognosis and frequently affects the craniofacial bones, ribs, and the bones of lower limb. Three percent of FD manifests as McCuneAlbright syndrome with skin pigmentation and hyperfunctioning endocrine disorders. ${ }^{4,6}$

Monostotic FD is more common which affects nearly $70 \%$ to $80 \%$ of patients with FD. ${ }^{4}$ Though the most common involvement site is femoral bone, all bones may be affected.

Pain, fracture, and bone deformity are common clinical features of $\mathrm{FD}^{7}$ Of the patients, 67\% reported local pain on the involved region. ${ }^{8}$ There are some reports about monostotic FD with upper extremity involvement. ${ }^{9,10}$ In one report, prominent shoulder pain and upper extremity deformity have
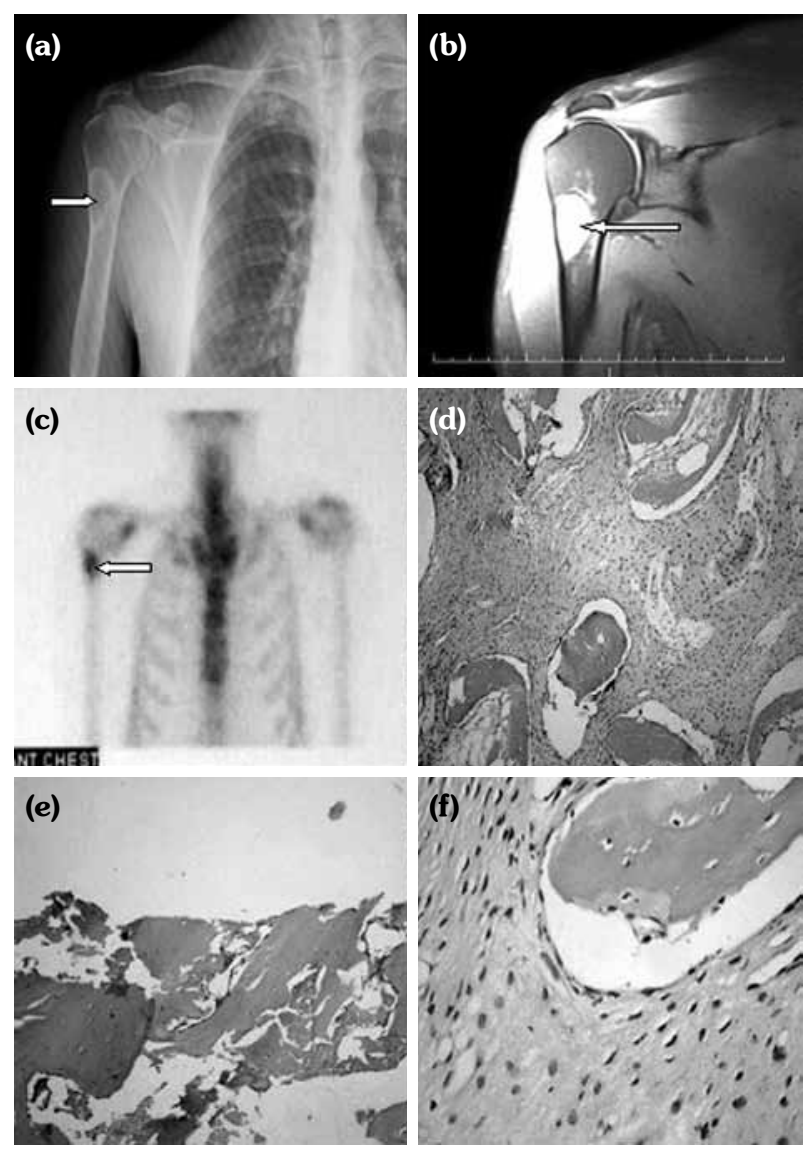

Figure 1. (a) Plain X-ray showed lytic area with hyperdense margin. (b) Shoulder magnetic resonance imaging showed hyperintense area at right humerus on $\mathrm{T}_{2}$ sequence. (c) $99 \mathrm{mTc}$-methylene diphosphonate bone scintigraphy showed focally increased radiotracer uptake. (d) Bone biopsy demonstrated delicate trabeculae of woven bone in moderately cellular fibrous matrix. (e) Bone biopsy demonstrated focal areas of degenerative bone fragments. (f) Bone biopsy demonstrated nonlamellar bone and bland spindle-cell fibrous stroma (H-E x 400). 
been reported ${ }^{9}$ while another case has presented with a deformity of forearm. ${ }^{10}$ However, both cases occurred in childhood period. Our patient was older and did not have any deformity. Besides, he presented with nonspecific shoulder pain. He had persisting pain both with motion and at rest. Physical examination of the current case revealed no specific findings other than minimally limited range of motion of shoulder joint.

Radionuclide bone scintigraphy is useful to demonstrate the extent of disease. ${ }^{7}$ Also, it is useful for the distinction between monostotic and polyostotic FD. Our case only had a significantly increased isotope uptake on humerus. Computed tomography and magnetic resonance imaging are additional modalities for further elucidating the extent of bony and neurovascular involvement. ${ }^{11}$ Bone biopsy is necessary in order to rule out malignancy and useful for preoperative planning. Both magnetic resonance imaging and bone biopsy were performed for the differential diagnosis in the current case.

Malignant transformation of FD occurs in about $0.4 \%$ to $4 \%$ of the cases. ${ }^{6}$ It is more likely to occur in polyostotic disease, in which the transformation is to osteosarcoma, fibrosarcoma, and chondrosarcoma. ${ }^{7}$ A study which evaluated the malign transformation of monostotic FD has revealed that the most common histological diagnosis was osteosarcoma. ${ }^{12}$ The authors of this study stated that diaphyses of long bones were the primary sites of malignant transformation in monostotic FD. It was also suggested that growth of mass, swelling, and pain might indicate sarcomatosis in patients with monostotic FD. Patients with monostotic FD of humerus had similar symptoms such as pain and swelling. Malign transformation to fibrosarcoma was reported in patients with humerus involvement. One of these patients had a pathologic humerus fracture and both had high pain intensity. ${ }^{12}$ Our case only reported nonspecific shoulder pain.

Nevertheless, pain may be the major problem in this group of patients. Although aggressive treatment is not necessary in all patients with monostotic FD, several medications including non-steroidal antiiflammatory drugs and narcotic analgesics have been prescribed for bone pain. Bisphosphonates have also been recommended for pain in order to decrease bone resorption in patients with FD. ${ }^{3,13,14}$

In general, bisphosphonates have promising results as the initial conservative treatment of FD. Most potent bisphosphonates such as pamidronate and zoledronic acid are preferred for the treatment of these patients. Increased number of osteoclasts and subsequent bone resorption may be seen in FD. Pamidronate, which is a potent inhibitor of osteoclasts, has positive results on pain, normalization of bone turnover, and increased bone density. ${ }^{4}$ Furthermore, there are some reports in the literature about the use of low dose alendronate for the treatment of FD and it has been stated that alendronate was effective for decreasing bone pain. ${ }^{15-17}$ The patient in the present study did not have increased bone resorption but had shoulder pain. Therefore, we preferred half dose of weekly alendronate sodium in order to prevent adverse effects. In recent years, some reports have been published about the use of denosumab, a human monoclonal antibody to receptor activator of nuclear factor-kappaB ligand, for the treatment of FD. ${ }^{18,19}$ Although there was significant improvement in pain and bone markers with use of denosumab, authors suggested that physicians should carefully consider biochemical and hormonal changes including hypophosphatemia, secondary hyperparathyroidism, and hypercalcemia. ${ }^{18,19}$ Surgery may be indicated if the patient has major bone deformity or mass compressing the adjacent tissue, causing visual loss or progressive dyspnea. ${ }^{4,14}$ Our case was not referred to surgery because of the normal bone turnover, low fracture risk, lack of other symptoms regarding compression, and good response to medical treatment.

In conclusion, FD may be a rare but important cause of shoulder pain. It should be kept in mind that the physical examination of shoulder does not always rule out a specific shoulder disease. Therefore, careful examination and imaging should be performed particularly in patients with persistent shoulder pain.

\section{Declaration of conflicting interests}

The authors declared no conflicts of interest with respect to the authorship and/or publication of this article. 


\section{Funding}

The authors received no financial support for the research and/or authorship of this article.

\section{REFERENCES}

1. Kelle B. Omuz patolojilerinde rehabilitasyon. Turkiye Klinikleri J Orthop \& Traumatol-Special Topics 2014;7:99-106.

2. Söker G, Söker E, Gülek B, Görgülü FF, Kelle B. An Atypical cause of shoulder pain. Turk $\mathrm{J}$ Phys Med Rehab 2014;60:271-3.

3. Ohno I, Higuchi C. Zoledronate Therapy for the Pathological Humeral Fracture in Polyostotic Fibrous Dysplasia: A Case Report. J Clin Med Res 2015;7:901-6.

4. Adetayo OA, Salcedo SE, Borad V, Richards SS, Workman AD, Ray AO. Fibrous dysplasia: an overview of disease process, indications for surgical management, and a case report. Eplasty 2015;15:6.

5. DiCaprio MR, Enneking WF. Fibrous dysplasia. Pathophysiology, evaluation, and treatment. J Bone Joint Surg Am 2005;87:1848-64.

6. MacDonald-Jankowski D. Fibrous dysplasia: a systematic review. Dentomaxillofac Radiol 2009;38:196-215.

7. Anitha N, Sankari SL, Malathi L, Karthick R. Fibrous dysplasia-recent concepts. J Pharm Bioallied Sci 2015;7:171-2.

8. Chapurlat RD, Gensburger D, Jimenez-Andrade JM, Ghilardi JR, Kelly M, Mantyh P. Pathophysiology and medical treatment of pain in fibrous dysplasia of bone. Orphanet J Rare Dis 2012;7:3.

9. Eren A, Cakar M, Erol B, Ozkurt A, Guven M. Focal fibrocartilaginous dysplasia in the humerus. J Pediatr
Orthop B 2006;15:449-52.

10. Gottschalk HP, Light TR, Smith P. Focal fibrocartilaginous dysplasia in the ulna: report on 3 cases. J Hand Surg Am 2012;37:2300-3.

11. Ricalde P, Horswell BB. Craniofacial fibrous dysplasia of the fronto-orbital region: a case series and literature review. J Oral Maxillofac Surg 2001;59:157-67.

12. Qu N, Yao W, Cui X, Zhang H. Malignant transformation in monostotic fibrous dysplasia: clinical features, imaging features, outcomes in 10 patients, and review. Medicine (Baltimore) 2015;94:369.

13. Ozdemir Kutbay N, Sarer Yurekli B, Kartal Baykan E, Baydur Sahin S, Saygili F. Characteristics and Treatment Results of 5 Patients with Fibrous Dysplasia and Review of the Literature. Case Rep Endocrinol 2015;2015:670809.

14. Thomsen MD, Rejnmark L. Clinical and radiological observations in a case series of 26 patients with fibrous dysplasia. Calcif Tissue Int 2014;94:384-95.

15. Chapurlat RD, Orcel P. Fibrous dysplasia of bone and McCune-Albright syndrome. Best Pract Res Clin Rheumatol 2008;22:55-69.

16. Li GD, Ogose A, Hotta T, Kawashima H, Ariizumi $\mathrm{T}, \mathrm{Xu} \mathrm{Y}$, et al. Long-term efficacy of oral alendronate therapy in an elderly patient with polyostotic fibrous dysplasia: A case report. Oncol Lett 2011;2:12391242.

17. Kitagawa $\mathrm{Y}$, Tamai $\mathrm{K}$, Ito $\mathrm{H}$. Oral alendronate treatment for polyostotic fibrous dysplasia: a case report. J Orthop Sci 2004;9:521-5.

18. Ganda K, Seibel MJ. Rapid biochemical response to denosumab in fibrous dysplasia of bone: report of two cases. Osteoporos Int 2014;25:777-82.

19. Boyce AM, Chong WH, Yao J, Gafni RI, Kelly MH, Chamberlain CE, et al. Denosumab treatment for fibrous dysplasia. J Bone Miner Res 2012;27:1462-70. 